\title{
O sujeito órfico no Livro de memórias, de Teixeira de Pascoaes: lembrança, desejo e saudade
}

\author{
Jorge Filipe Ressurreição*
}

\author{
É um poema de saudade, \\ mergulhando nos seres e no mundo- \\ e ainda a escorrer. \\ Raul Brandão
}

O Livro de memórias, de Teixeira de Pascoaes, retrata um mundo, o mundo do narrador, povoado de lembranças que se presentificam constantemente por serem parte integrante daquele que narra. De facto, se esta concretização é característica do género memorialístico, com o recurso à hipotipose (definida tradicionalmente pela expressão ciceroniana ponere ante oculos), nesta obra de Pascoaes parece ser um fator em torno do qual tudo gira e do qual tudo deriva. De facto, a obra de Pascoaes centra-se principalmente no sujeito, do qual tudo emerge e para o qual tudo regressa. E esse tudo corporiza-se e esfuma-se "à luz da imaginação evocadora" (PASCOAEs, 2001, p. 37), a qual é transversal à totalidade da obra de Teixeira de Pascoaes. Por exemplo, é ela, "a imaginação evocadora", que, em Regresso ao Paraíso, mas de modo diverso, faz Adão e Eva, quando descem às profundezas do inferno, verem figuras como Espártaco, Giordano, Ugolino, Tântalo, Diogo Coelho, D. Pedro I, Roby, Mouzinho, Antero de Quental, Eça de Queirós, Camilo Castelo Branco, Soares dos Reis, Viriato, D. Afonso Henriques, Mestre de Avis, a Menina e Moça, Bernardim Ribeiro, Vasco da Gama, o Adamastor, o Encoberto, Camões Almas "que deixaram / Um rasto escuro e fúnebre na História / Ou luminoso rasto na Legenda" (PASCOAES, 1986, p. 30-32) - e o seu filho, Caim. Esta descida aos infernos fará com que o casal primordial recorde o paraíso perdido. Consequentemente, esta lembrança será responsável pelo desejo - mais tarde alcançado - de regressar a esse paraíso que outrora habitaram. Deve notar-se, porém, que este é agora um novo paraíso: a divindade já não é o antigo Deus, mas a Saudade, pois nela há a lembrança do passado e o desejo do futuro (PASCOAES, 1986, p. 164-165).

A evocação do passado é, de facto, constante no Livro de memórias, pois, tal como o sujeito lembra, ela "dissipa as trevas do tempo e ressuscita os mortos" (PAsCOAEs, 2001, p. 37), e, ao ressuscitá-los, torna-os figuras presentes e libertas das correntes desse passado. O próprio narrador dá conta disto quando, ao falar

Mestre em Estudos Românicos (Literatura Portuguesa) pelo Centro de Estudos Clássicos da Universidade de Lisboa. E-mail: jressurreicao@letras.ulisboa.pt 
das lembranças, sugere: "algumas, tão vivas, com esta força de presença que é um privilégio das coisas materiais" (PASCOAEs, 2001, p. 37). Este poder da "imaginação evocadora" (PASCOAES, 2001, p. 37) fará com que o sujeito traga ao presente imagens da sua infância, esse "período mitológico" (PAscoAes, 2001, p. 60), essa "idade de oiro que foi, mais tarde, cantada por Virgílio" (PAscoaes, 2001, p. 68). Ao colocar a sua infância em época anterior a Vergílio, ${ }^{1}$ poeta latino do século I a.C., o sujeito admite que o nascimento do mundo e o seu próprio nascimento se deram simultaneamente: "Tínhamos sete anos, eu e o mundo" (PAsCOAEs, 2001, p. 55).

Posto isto, proponho atentar no sujeito do primeiro capítulo ${ }^{2}$ do Livro de memórias, de Teixeira de Pascoaes, como um sujeito órfico, que, pela escrita, pretende trazer a sua Eurídice - isto é, a infância ou as imagens que a compõem - de volta ao tempo presente, resgatando-a das amarras do passado (o Inferno). E, se atentarmos em outro texto de Pascoaes, "Eurídice e Orfeu", inserido em Verbo escuro, lemos que "através do nosso sentimento, Eurídice é a Lembrança e o Desejo é Orfeu... / O Desejo, incidindo sobre a Lembrança, dá-lhe presença animada e criadora" (PASCOAes, 1999, p. 118). Assim, o desejo do sujeito órfico do Livro de memórias de tentar resgatar a infância - Lembrança - mais não é do que dar-lhe presença, como vimos, através da "imaginação evocadora" (PASCOAEs, 2001, p. 37).

O texto "Eurídice e Orfeu" da obra Verbo escuro, de Teixeira de Pascoaes, reinterpreta o mito antigo da catábase de Orfeu - tematizado por diversos autores da Antiguidade Clássica, sendo os principais Vergílio, nas Geórgicas, e Ovídio, nas Metamorfoses - à luz da mundividência pascoaesiana. ${ }^{3}$ Antes de me debruçar sobre a obra memorialística, considerarei, ainda que brevemente, este escrito de Verbo escuro, de modo a perceber qual é a interpretação do mito vergiliano do poeta de Marânus.

"Eurídice e Orfeu" encontra-se estruturado por pontos, como todos os textos da obra em que se insere, perfazendo um total de treze. No primeiro ponto, o narrador remete logo o leitor, ainda que indiretamente, para o mito de Orfeu, uma vez que refere a ação destruidora da luz do olhar e a ação também de se "ser visto" que implica o "quase morrer" (PASCOAEs, 1999, p. 117). Como narram os autores antigos, é o movimento do olhar de Orfeu na direção de Eurídice, no momento em que a trazia de volta ao mundo dos vivos, que faz com que esta se esfume e de novo volte ao reino de Plutão, o Inferno, para de lá não mais sair. Faz de seguida o

\footnotetext{
Ao citar o nome do autor latino, uso a forma escrita como esta surge no texto original. No entanto, quando escrevo texto de minha autoria e refiro o seu nome, utilizo a forma Vergílio uma vez que em latim se escrevia Vergilius.

2 Esta seleção prende-se com o facto de este capítulo ser "uma espécie de preposição ideativa de todo ele [do livro], em que o narrador o resume em fragmentos desordenados e impetuosos, num estilo especulativo e sentencioso" (FrAnco, 2000, p. 95).

3 Este texto não é exemplo único da reinterpretação do mito na obra de Pascoaes. Também no livro As Sombras, encontramos um poema, estruturado em duas secções, intitulado "A Sombra de Eurídice" (PAsCOAES, 1996, p. 88-89).
} 
narrador uma breve reflexão sobre o que é definitivo e a "nublosa inspiração" que é "matéria de novas criações" (PASCOAES, 1999, p. 117).

No ponto IV do texto, o sujeito define a sua "essência trágica da vida", que é a "dor": para ele, esta advém do ódio entre a "luz da alma" e a "luz dos olhos" (PAscoAes, 1999, p. 117). Esta "inimizade" será esclarecida no seguimento do texto, pois, logo no ponto seguinte, o narrador refere Vergílio - e denomina-o como "o espírito moderno da Antiguidade" (PAscoAes, 1999, p. 117, grifo no original) -, informando que o poeta "cantou a lenda sublime de Eurídice e Orfeu" (PAscoAes, 1999, p. 117). A interpretação de Pascoaes do mito órfico inicia-se verdadeira e diretamente neste ponto, pois afirma ser esta lenda o "eterno conflito cósmico entre a alma e o corpo" (PASCOAEs, 1999, p. 117). Tal conflito encontra paralelo na "inimizade" entre a "luz da alma" e a "luz dos olhos" (PascoAes, 1999, p. 117). Desta forma, para Pascoaes, existem dois polos no conflito patente no mito antigo: por um lado, Orfeu, a "luz dos olhos", o corpo, e, por outro lado, Eurídice, a "luz da alma" (PASCOAEs, 1999, p. 117). Do encontro entre estes dois opostos, resultaria então a "dor", uma vez que é o sofrimento que surge no momento em que a "luz do olhar" de Orfeu incide sobre a "luz da alma" (PascoAes, 1999, p. 117) de Eurídice e esta retorna para o reino de Plutão.

Depois de declarar que, ao contrário de Vergílio, que "atribui o papel dramático a Orfeu", para ele "é maior a angústia de Eurídice, quando, já perto do amante, se esvai, de novo, em sombra pálida" (PASCOAEs, 1999, p. 117) e que "O desencanto de Eurídice foi o desencanto absoluto. Revelou-lhe que a vida é ainda menos do que a morte" (PASCOAES, 1999, p. 118), o narrador afirma, no ponto X do texto:

X. Mas, através do nosso sentimento, Eurídice é a Lembrança e o Desejo é Orfeu... O Desejo, incidindo sobre a Lembrança, dá-lhe presença animada e criadora. A Lembrança é a fonte da esperança (PAscoAes, 199, p. 118).

Este ponto do texto interessa, como já ficou expresso anteriormente, pela aproximação que Teixeira de Pascoaes faz entre o mito antigo e a memória e ainda entre o mito e a saudade. Mais interesse ganha este ponto, quando, ao ler a primeira edição de Verbo escuro, deparamos com uma assinalável diferença para o ponto X que transcrevi. Em 1914, este ponto estava assim patente no texto:

X. Mas atravez da nossa alma lusiada, Euridice é a Lembrança e o Desejo é Orfeu... O Desejo, incidindo sobre a Lembrança, dá-lhe presença viva, ergue, em alto relêvo colorido, o seu ilusorio vulto de sombra... A imagem espiritual como que abandona o Reino da Memoria, a fim de voltar a ser, com mais vida e beleza, o antigo corpo que a projectou (PAscoAes, 1914, p. 123-124).

Embora as diferenças textuais sejam evidentes, bem como a extensão, pareceme que a ideia é a mesma, tendo apenas Pascoaes trabalhado para o dizer de forma 
mais depurada e sucinta. De facto, interessa reter o poder do desejo de um sujeito sobre a lembrança, a memória, de tal forma forte que faz com que esta deixe ser "imagem espiritual" para ser "presença viva" "em alto relêvo colorido" (PAscoAes, 1914, p. 123), "abandona[ndo] o Reino da Memoria" (PAscoAes, 1914, p. 123-124).

No ponto seguinte, outro conceito é trazido à colação pelo narrador: a Saudade. ${ }^{4}$ A definição do termo saudade é dada pelo escritor, citando Duarte Nunes de Leão, em "O espírito lusitano ou o saudosismo", que segundo informa Pinharanda Gomes em nota, é "o texto da conferência de propaganda da Renascença Portuguesa" (PAsCoAES, 1988, p. 43): "Saudade é a lembrança de alguma coisa com desejo dela" (PASCOAEs, 1988, p. 50). Esta apropriação do significado de saudade para Duarte Nunes Leão tem o seu sentido:

A Saudade pelo desejo (desejar é querer, e querer é esperar), em virtude da própria natureza do Desejo, é também Esperança, e pela Dor é Lembrança. Pela esperança e pelo desejo, a Saudade é Vénus; pela dor e pela lembrança é a Virgem Dolorosa (PASCOAES, 1988, p. 47).

Deste modo, a apropriação do mito para a sua defesa da Saudade enquanto expressão máxima da alma lusíada encontra assim justificação:

XI. Esta antiga tragédia mitológica, transfundida para o sangue duma Raça, idealizou-se, humanizou-se, provocando o advento redentor da Virgem Lusíada - a Saudade (PASCOAes, 1999, p. 118).

Estamos assim providos dos conceitos básicos (Desejo, Lembrança, Saudade) para compreender o Livro de memórias, uma vez que esta obra mais não é do que o desejo do sujeito recaindo sobre a sua memória, dando-lhe assim presença viva.

No primeiro capítulo do Livro de memórias, o sujeito começa por se localizar no tempo - "agora mesmo"; "Ontem"; "Estamos ainda no Agosto" (PAscoAes, 2001, p. 37) - e no espaço - "passeio do jardim" (PAscoAes, 2001, p. 37). As expressões temporais, dando a ilusão de que o ato de escrita é imediato, e as expressões espaciais, inserindo o sujeito num espaço limitado, constroem um cenário melancólico pela presença da "primeira folha morta, num passeio do jardim" (PASCOAES, 2001, p. 37) e da "primeira névoa cinzenta" (PAscoAes, 2001, p. 37) que fazem o narrador afirmar: "Estamos ainda no Agosto e é já outono" (PAsCOAEs, 2001, p. 37). No dizer de Paula Morão (2011, p. 98), esta construção ganha relevo, tendo em conta o que se segue no Livro de memórias:

[...] a deambulação no jardim, longe de constituir um registo de circunstâncias acidentais, propicia o recentramento e cumpre a função de pausa ou de intervalo a preparar a reflexão retrospectiva.

\footnotetext{
4 Sobre a saudade na obra de Teixeira de Pascoaes, leia-se Sá (1992, p. 92-107).
} 
Este cenário melancólico abarca o escritório para onde o sujeito se dirige de seguida. Referir a construção de um cenário melancólico é o mesmo que dizer que é o sujeito quem tem a melancolia dentro de si, dando ao espaço ao seu redor essa característica: assim o jardim como o escritório.

Com a entrada no escritório, o sujeito "cess[a] o movimento para dar início à longa reflexão retrospectiva que constitui o Livro de memórias" (MorÃo, 2011, p. 98). Esta passagem do exterior para o interior, do jardim para o escritório, poderá ser entendida como uma passagem órfica. Orfeu, para poder retomar Eurídice, sua mulher, desce ao mundo subterrâneo. Assim, o sujeito do Livro de memórias, para poder recordar a infância, "esse período divino" (PASCOAEs, 2001, p. 81), ${ }^{5}$ tem de descer ao mais fundo de si mesmo. Com efeito, notamos que, lentamente, "os contornos das coisas vão-se esfumando cada vez mais, deslizando para a dimensão visionária do sujeito, que tudo contamina e investe com o seu olhar melancólico" (MORÃO, 2011, p. 98):

Velhos móveis enigmáticos revestem-se duma sombra dolorida, animamse e falam-me ${ }^{6}$ de antigas pessoas que eu amei. Vejo-as à luz da imaginação evocadora: uma luz que dissipa as trevas do tempo e ressuscita os mortos. Nesta cadeira de pau-preto, minha avó desfia as contas dum rosário. Ouço-a: Avé, Maria... Padre Nosso... E ouço ainda os passos do meu avô, no corredor. Alvejam ainda, no ar, as mãos que dependuraram, na parede, a Minerva bordada a oiro, por minha tia Gertrudes (PAscoAes, 2001, p. 37).

Através de "hipálages sucessivas" (Morão, 2011, p. 99), as coisas vão ganhando uma carga vital que só o íntimo do sujeito lhes poderia dar. Paralelamente, os mortos, entes perdidos da sua infância, ressuscitam, tal como Eurídice. Uma vez mais, a descida de Orfeu aos infernos encontra paralelo, no texto de Pascoaes, com a descida do sujeito ao mais fundo de si, deixando que a "luz da imaginação evocadora [...] dissip[e] as trevas do tempo e ressuscit[e] os mortos".7

Logo de seguida, o sujeito dá conta de dois tipos de situações que acontecem diante dele. É como se as várias figuras que povoam a memória infantil do sujeito fossem uma dupla face de Eurídice: aquela que se esfuma quando Orfeu a olha "esfumam-se perfis desconhecidos" (PAscoAes, 2001, p. 37) - e aquela que lhe aparece aquando da sua ida ao mundo de Plutão - "e desenham-se outros conhecidos" (PASCOAES, 2001, p. 37). Esta última face de Eurídice torna-se ainda mais presente quando o narrador informa:

5 Sobre o peso da infância na obra de Teixeira de Pascoaes, leia-se Coelho (1999, p. 35-39 e p. 163175).

6 Na edição utilizada lê-se "falam-se", o que, concordando com Paula Morão (2011, p. 98), parece ser uma gralha, uma vez que na primeira edição lê-se "falam-me", sendo mais coerente. Assim, uso aqui esta forma da primeira edição, em detrimento da forma que se encontra na edição utilizada.

7 Para a construção textual desta viagem a si mesmo, note-se a presença dos verbos no presente do indicativo ("revestem-se"; "animam-se"; "falam-me"; "Vejo-as"; "dissipa”; "ressuscita"; "desfia"; "Ouço-a"; "ouço"; "Alvejam”). 
Estes [os perfis conhecidos] [...] mais um esforço e alcançariam a plena realidade, aquele corpo material e espiritual: material, porque podemos tocá-lo; espiritual, porque dimana uma luz inapreensível de simpatia ou antipatia que nos aquece ou arrefece, e é carne e sangue (PASCOAES, 2001, p. 37).

Assim, ganha relevo a presença de Eurídice, que, como pudemos verificar, para Teixeira de Pascoaes, é a figura do mito que mais relevo deveria ter, uma vez que "é maior a angústia de Eurídice" (PAsCOAEs, 1999, p. 117) do que a de Orfeu, neste excerto: os perfis conhecidos precisariam, da parte do sujeito, de "mais um esforço" para "alcançar[em] a plena realidade", tal como Eurídice da parte de Orfeu. Como sabemos, é já perto do mundo dos vivos que Orfeu a olha e a vê esfumar-se na "plutónica penumbra" (PAscoAes, 1999, p. 118). Com efeito, bastaria que Orfeu fizesse "mais um esforço" para que a ninfa ganhasse "aquele corpo material e espiritual", de modo a que o esposo lhe pudesse tocar e visse nela "uma luz inapreensível de simpatia ou antipatia que nos aquece ou arrefece, e é carne e sangue" (PAscoAes, 2001, p. 37).

Como tenho vindo a fazer notar, se a infância do sujeito se aproxima de Eurídice, este encontra um certo paralelo com Orfeu, não só na descida aos infernos em busca da ninfa, mas também no poder da palavra que, para o narrador do Livro de memórias, é uma forma de fixar pela escrita a infância, e que, para Orfeu, é a forma com que inebria o deus do mundo subterrâneo, de modo a dele alcançar a autorização para trazer de novo Eurídice ao mundo dos vivos, projeto que só o olhar trai. Neste sentido, afirma Silvina Rodrigues Lopes (1990, p. 185):

É a partir das trevas que as coisas se dão a ver, é porque participamos na linguagem que elas são mais do que formas e cores, fazem sentido. A memória de formas e cores é duplicada pela memória das palavras, e por isso ver é sempre "quase ver", o olhar repartido entre as trevas e a luz. [...] A anulação de um dos polos, trevas ou luz, significa a impossibilidade de ver, ou que "ver é não ver", seja pela perda do sentido, seja pelo exercício de um domínio subjectivo (Pascoaes interpreta o olhar de Orfeu como exercício do desejo de domínio que vai implicar a impossibilidade de ver, concretizada no desaparecimento de Eurídice - VE, 157).

O narrador inicia o quarto parágrafo do primeiro capítulo do Livro de memórias declarando que "Os mortos ressuscitam ao luar da tristeza evocadora" (PAsCOAEs, 2001, p. 37). Esta sentença aplica-se ao sujeito que, assim, se alia a Orfeu. Com efeito, a "tristeza evocadora" é, em ambos, transmitida por meio da palavra poética. Lemos nas Metamorfoses, de Ovídio:

Através de povos insubstanciais e fantasmas dos sepultados, chegou ao pé de Perséfone e do senhor que governa o desagradável reino das sombras. E dedilhando as cordas, assim cantou (OvíDIo, 2007, p. 245). 
Depois de Orfeu pedir aos deuses infernais que "torn[em] a tecer o destino apressadamente cortado de Eurídice” (OvíDIo, 2007, p. 246), é descrita a reação geral ao seu canto:

Tântalo não buscou

apanhar a água fugidia, a roda de Ixíon imobilizou-se de pasmo, os aves pararam de debicar o fígado, as Bélides não cuidaram das vasilhas, e até tu, Sísifo, te sentaste sobre o teu pedregulho. Conta-se que então, pela primeira vez, as faces das Euménides se molharam de lágrimas, conquistadas pelo cantar dele (Ovídio, 2007, p. 246).

Em Vergílio, a mesma reação ao canto de Orfeu é exposta nos seguintes termos:

Mas as sombras ligeiras, movidas pelo (seu) canto, acorriam das habitações profundas do Érebo, e os fantasmas daqueles privados de luz ( $d a$ vida), (tantos) quantos milhares de aves se escondem nas folhagens, logo que a Estrela da Tarde ou a chuva do Inverno as afugenta dos montes. [...] Além disso, as próprias moradas (infernais), e os mais profundos tártaros da morte, e as Euménides entrelaçadas nos cabelos de cobras azuladas; e Cérbero abrindo as três goelas as conteve, e o movimento da roda de Ixião parou com o (cessar do) vento (Virgílio, 1966, p. 89).

Em ambos os textos clássicos, a palavra do poeta, através do canto, apropria-se de todos os habitantes do reino dos mortos e, consequentemente, faz com que os deuses subterrâneos acedam ao pedido de Orfeu.

Assim, também no Livro de memórias, o sujeito alcança a sua infância pela palavra, não cantada mas escrita, que, por sua vez, é o produto da memória subordinada à realidade, refletindo o "luar da tristeza evocadora" (PASCOAES, 2001, p. 37):

Os mortos ressuscitam ao luar da tristeza evocadora. Toda a alma triste dá luar; e os fantasmas aparecem junto dela. É a memória que se povoa de lembranças; algumas, tão vivas, com esta força de presença que é um privilégio das coisas materiais (PAsCOAEs, 2001, p. 37).

Por conseguinte, inevitavelmente, o sujeito "trat[a] de proceder por recollectio, ao inventário de todos os entes queridos, enumerando-os para os presentificar", "são literalmente chamados à presença daquele que os evoca em pose visionária pelas frequentes apóstrofes" (MorÃo, 2011, p. 100): "E a turba cresce. Aqueles vultos ganham uma existência exterior; enchem o meu escritório, ocupam um lugar no mundo" (PASCOAES, 2001, p. 40). E com eles cresce a saudade que "retoca certas imagens da memória e acende uma auréola divina em volta del[e]s" (PAscoAes, 2001, p. 40). O "sentimento-ideia" (SÁ, 1992, p. 26) mais tematizado e difundido 
por Teixeira de Pascoaes surge inevitavelmente neste seu Livro de memórias porque, tal como esclarece em "Eurídice e Orfeu", ele nasce do desejo incidindo sobre a lembrança:

Estas imagens confundem-se comigo, porque, no pequeno espaço do meu corpo, cabe outro espaço que vai até onde vai o pensamento. Sois comigo! E que distância nos separa. Que saudade! Mas viveis desta saudade, desta substância ilusória em que o meu ser se continua e ultrapassa os limites da Existência. [...] Como eu adoro esta imagem apagada na distância, onde os fantasmas representam o drama da saudade! Drama ou tragédia? Tragédia, porque os personagens excedem o homem, como os deuses e os heróis (PASCOAEs, 2001, p. 39-40).

O narrador do Livro de memórias afirma neste excerto que, no espaço do seu corpo, há um outro onde se encontram as imagens, os espectros. Esse lugar, onde ele e estes se confundem, é o reino de Plutão, a memória do passado, onde ele desce, qual Orfeu, para os voltar a ter com ele: "Sois comigo!" Porém o sujeito tem noção da distância que o separa dos fantasmas, o que não o impede de aceder a eles pois a saudade, enquanto força que lhes dá presença, permite-lhe "continua[r] e ultrapassa[r] os limites da Existência”, isto é, uma vez mais, Orfeu que supera o humanamente possível e desce aos infernos em busca de Eurídice. Paula Morão (2011, p. 97-98) identifica "esta operação mnésica" com certos momentos bíblicos:

[...] as formas e as figuras acedem à luz a partir das trevas, como na criação narrada no Génesis; a reunião das almas no Vale de Josafat no Dia do Juízo Final e o poder de ressuscitar os mortos, por sua vez, referem-se a vários textos sagrados, todos insistindo, afinal, no grande cenário arquetípico do combate vencedor sobre a morte.

A aproximação que fiz do sujeito do Livro de memórias à personagem mítica de Orfeu pretende ser um contributo para o entendimento de um livro que, inserindose no género memorialístico, em quase tudo foge às características que esperaríamos encontrar numas memórias de autor. Sobre a questão do género no Livro de memórias, Paula Morão (2011, p. 97) afirma:

[...] não se encontram, senão remotamente, as características canónicas do memorialismo, como a seriação cronológica de eventos, o escopo objectivante ou a distanciação de uma escrita que se afasta do sujeito para privilegiar os factos que o enquadram e constituem.

De facto, o tratamento do tempo e do espaço é secundário em relação ao próprio sujeito, uma vez que "[e]ste está muito mais interessado em reflectir sobre si próprio, que sobre os valores e os acontecimentos da época" (FrANCO, 2000, p. 95). Por isto, parece-me que o Livro de memórias de Teixeira de Pascoaes é uma obra 
que "ultrapassa os limites da [sua] Existência" (PAscoAes, 2001, p. 39), enquanto um escrito do género memorialístico, abrindo horizontes de leituras bastante mais complexos.

\section{Referências}

Coelho, Jacinto do Prado. A poesia de Teixeira de Pascoaes e outros escritos pascoaesianos. A educação do sentimento poético. Organização, revisão e fixação do texto de António Cândido Franco e Luís Amaro. Prefácio de Fernando Guimarães. Porto: Lello, 1999.

Franco, António Cândido. A literatura de Teixeira de Pascoaes. Lisboa: Imprensa Nacional-Casa da Moeda, 2000.

Lopes, Silvina Rodrigues. O excesso por defeito - A escrita da memória em Teixeira de Pascoaes. In: Lopes, Silvina Rodrigues. Aprendizagem do incerto. Lisboa: Litoral, 1990. p. 175-195.

Morão, Paula. O Livro de memórias de Teixeira de Pascoaes. In: Morão, Paula. $O$ secreto e o real: ensaios sobre literatura portuguesa. Lisboa: Campo da Comunicação, 2011. p. 97-108.

Ovídıo. Metamorfoses. Tradução de Paulo Farmhouse Alberto. Lisboa: Cotovia, 2007 .

Pascoaes, Teixeira de. Euridice e Orfeu. In: Pascoaes, Teixeira de. Verbo escuro. Porto: Renascença Portuguesa, 1914. p. 121-124.

Pascoaes, Teixeira de. Livro de memórias. Coimbra: Atlântida, 1928.

Pascones, Teixeira. Regresso ao Paraíso. Introdução de Agostinho da Silva. Lisboa: Assírio \& Alvim, 1986.

Pascoaes, Teixeira de. O espírito lusitano ou o saudosismo. In: Pascoaes, Teixeira de. A saudade e o saudosismo. Compilação, introdução, fixação do texto e notas de Pinharanda Gomes. Lisboa: Assírio \& Alvim, 1988. p. 43-58.

Pascoaes, Teixeira de. A sombra de Eurídice. In: Pascoaes, Teixeira de. As sombras. Lisboa: Assírio \& Alvim, 1996. p. 88-89.

Pascones, Teixeira de. Eurídice e Orfeu. In: Pascones, Teixeira de. Senhora da noite/Verbo escuro. Lisboa: Assírio \& Alvim, 1999. p. 117-119.

Pascoaes, Teixeira de. Livro de memórias. Prefácio de António Cândido Franco. Lisboa: Assírio \& Alvim, 2001.

SÁ, Maria das Graças Moreira de. Estética da saudade em Teixeira de Pascoaes. Lisboa: Instituto de Cultura e Língua Portuguesa, 1992. 


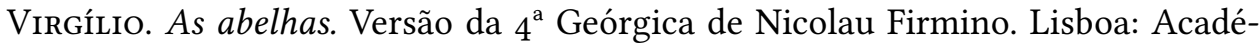
mica de D. Felipa; Rio de Janeiro: H. Antunes, 1966.

Recebido em 24 de outubro de 2017.

Aprovado em 25 de março de 2018.

\section{Resumo/Abstract/Resumen}

O sujeito órfico no Livro de memórias, de Teixeira de Pascoaes: lembrança, desejo e saudade

\section{Jorge Filipe Ressurreição}

O Livro de memórias, de Teixeira de Pascoaes, retrata um mundo, o do narrador, povoado de lembranças que se presentificam constantemente por serem parte integrante daquele que narra. Para isso, o autor usa vários processos retóricos que o auxiliam na sua acção de evocar o passado. Contudo, mais do que simplesmente evocar, o sujeito pretende retirar das amarras do passado as imagens que compõem a sua memória e trazê-las de novo para junto de si, "dissipa[r] as trevas do tempo e ressuscita[r] os mortos", como diz o próprio. Deste modo, propomo-nos atentar no sujeito do primeiro capítulo do Livro de memórias como um sujeito órfico, que, pela escrita, pretende trazer a sua Eurídice - isto é, a sua infância ou as imagens que a compõem - de volta ao tempo presente, resgatando-a do passado (o Inferno). A aproximação do sujeito do Livro de memórias à personagem mítica de Orfeu pretende ser um contributo para o entendimento de um livro que, inserindo-se no género memorialístico, em quase tudo foge às características que esperaríamos encontrar numas memórias de autor.

Palavras-chave: lembrança, memória, saudade, presentificação, Orfeu, Teixeira de Pascoaes.

The Orphic subject in Livro de memórias, by Teixeira de Pascoaes: keepsake, desire and missing

\section{Jorge Filipe Ressurreição}

Livro de memórias, by Teixeira de Pascoaes, depicts the narrator's world populated with memories that constantly present themselves as being an integral part of the narrator. To achieve this, the author uses several rhetorical processes which help him in his evocation of the past. However, rather than simply evoking, the subject seeks to remove from the bonds of the past the images that constitute his memory and bring them back to him, "to dissipate the darkness of time and to raise the dead", as he says. In this way, I suggest we view the subject of the first chapter of 
Livro de memórias as an orphic subject, who, through writing, aims to bring back his Eurydice - that is, his childhood or the images that make it up - back to the present time, rescuing it from the past (Hell). The likening of the subject to the mythical character, Orpheus, intends to contribute to the understanding of a book that in almost every way escapes the characteristics which one would expect to find in authors' memoires.

Keywords: keepsake, memory, missing, presentification, Orfeu, Teixeira de Pascoaes.

El sujeto órfico en Livro de memórias, de Teixeira de Pascoaes: recuerdo, deseo y nostalgia

\section{Jorge Filipe Ressurreição}

Livro de memórias, de Teixeira de Pascoaes, retrata un mundo, el del narrador, con recuerdos que se vuelven presentes constantemente por ser parte del que narra. Para ello, el autor utiliza varios procesos retóricos que le ayudan a evocar el pasado. Más que evocarlo, el sujeto quiere substraer de los vínculos del pasado las imágenes que componen su memoria y traerlas de nuevo a su lado, "disipa[r] las tinieblas del tiempo y resucita[r] a los muertos”, como dice él mismo. Así, nos proponemos observar el sujeto del primer capitulo de Livro de memórias como un sujeto órfico, que por su forma de escribir pretende traer a su Eurídice - esto es, a su infancia o a las imágenes que la componen - de vuelta al ahora, rescatándola del pasado (el Infierno). La aproximación del sujeto de Livro de memórias al personaje mítico de Orfeo pretende ser una contribución para la comprensión de un libro que, incluyéndose en el género memorialístico, se aleja casi totalmente de las características que esperaríamos encontrar en unas memorias de autor.

Palabras clave: recuerdo, memoria, anhelo, presentificación, Orfeo, Teixeira de Pascoaes. 